\title{
Groundwater contributions in water-salt balances of the lakes in the Badain Jaran Desert, China
}

\author{
GONG Yanping ${ }^{1}$, WANG Xusheng ${ }^{1 *}$, HU B Xiao ${ }^{1}$, ZHOU Yangxiao ${ }^{2}$, HAO Chunbo ${ }^{1}$, WAN \\ $\mathrm{Li}^{1}$ \\ ${ }^{1}$ MOE Key Laboratory of Groundwater Circulation and Evolution, China University of Geosciences, Beijing 100083, China; \\ ${ }^{2}$ Water Engineering Department, UNESCO-IHE Institute for Water Education, DA Delft 2601, Netherland
}

\begin{abstract}
Groundwater-fed lakes are essential for the ecology in arid and semiarid regions. As a typical arid region, the Badain Jaran Desert (BJD) is famous in the world for the presence of a large number of groundwater-fed saline lakes among the mega dunes. Based on the up to date geological surveys and observations, this study analyzed the groundwater contributions in water-salt balances of the lakes in the desert. We found different types of springs, including the sublacustrine springs that indicate an upward flow of groundwater under the lakebed. A simplified water balance model was developed to analyze the seasonal variations of water level in the SumuBarunJaran Lake, which revealed an approximately steady groundwater discharge in the lake and explained why the amplitude of seasonal changes in lake level is less than $0.5 \mathrm{~m}$. In addition, a salt balance model was developed to evaluate the salt accumulations in the groundwater-fed lakes. The relative salt accumulation time is $800-7,000$ years in typical saline lakes, which were estimated from the concentration of $\mathrm{Cl}^{-}$, indicating a long history evolution for the lakes in the BJD. Further researches are recommended to provide comprehensive investigations on the interactions between the lakes and groundwater in the BJD.
\end{abstract}

Keywords: arid region; groundwater-fed lake; spring; water level change; salinity

Citation: GONG YanPing, WANG Xusheng, HU B Xiao, ZHOU Yangxiao, HAO Chunbo, WAN Li. 2016. Groundwater contributions in water-salt balances of lakes in the Badain Jaran Desert, China. Journal of Arid Land, 8(5): 694-706. doi: $10.1007 / \mathrm{s} 40333-016-0086-8$

Groundwater-fed lakes are widely distributed in arid and semiarid regions where streams and rivers are rare, which usually ended as saline systems, such as saline lakes, salinas, salt pans and playas, after a long history in the circumstances of that evaporation is the only way of water loss and exceeds precipitation (Rosen, 1994; Yechieli and Wood, 2002). As a typical desert area, the Badain Jaran Desert (BJD) in China, is famous in the world for about 100 groundwater-fed lakes that exist among the gigantic sand dunes. Most of them are saline lakes. Where does groundwater come from in the BJD? This issue has attracted a lot of interests in the last decade (Chen et al., 2004; Mischke et al., 2005; Ma and Edmunds, 2006; Gates et al., 2008; Yang et al., 2010; Wang et al., 2014; Zhang et al., 2015). A comprehensive review on the issue was presented by Dong et al. (2013).

How groundwater influences the lakes in the BJD is an unresolved question besides the groundwater origination issue. It involves three questions: (1) How groundwater discharges into the lakes: uniform or heterogeneous? (2) How groundwater controls the water balance of the lakes at different time-scales? (3) What are the fates of the lakes under the continuous salt import from 
groundwater discharge? The development of the lakes in the BJD, i.e. the changes in the area, depth and salinity of a lake or the change in the number of lakes, is highly dependent on the processes of groundwater discharge. Thus, the answers to the above three questions can help us to understand the water-salt balances of the lakes and to develop a more reasonable prediction on the future of the lakes in the context of the global changing climate system.

The role of groundwater in the BJD lakes has been investigated since 1960s (Sun et al., 1961; Gao et al., 1981). Due to all difficulties in such a large desert with relatively low technique level, only a few observations were made in the first 30 years. Wang (1990) reported that springs were found on both the edge of lakes and the islets in the centers of some lakes. The total dissolved solids (TDS) in the spring water was generally less than $1.0 \mathrm{~g} / \mathrm{L}$, which is significantly less than that in the lake water. Wang (1990) hypothesized a local hydrological circulation between sand dunes in which groundwater originate from infiltration of precipitation on the dunes and discharge to the nearby lakes. Yang (2002) compared the chemical characteristics between lake water and groundwater, including $\mathrm{pH}$, TDS and the concentrations of different ions. The findings supported the hypothesis proposed by Wang (1990). During 1990-2010, most of the studies focused on stable isotopic compositions $(2 \mathrm{H}, 3 \mathrm{H}$ and $18 \mathrm{O})$ of groundwater and lake water samples (Geyh et al., 1998; Chen et al., 2004; Ma and Edmunds, 2006; Gates et al., 2008). In particular, Chen et al. (2004) suggested that the shallow groundwater in the BJD was recharged by deep groundwater originated from Qilian Mountains (more than $300 \mathrm{~km}$ away from the desert). However, no hydraulic evidence was provided to support the assumption. In recent years, the seasonal variations of the number and the size of the lakes in this area were investigated using remote sensing images (Zhu et al., 2011; Jin et al., 2014). Inter-annual variations of the total lake areas (Zhang et al., 2015) and the water levels in some lakes (Jiao et al., 2015) were also identified using remote sensing method. It demonstrated that the water balance of the lakes were not in a steady state. The variations in lake water levels could not be fully interpreted by the variations of meteorological factors (Jiao et al., 2015; Zhang et al., 2015), indicating that groundwater may play an important role in the water balance of these lakes.

Since 2012, a new survey of groundwater-lake interactions in the BJD was carried out by a research group from China University of Geosciences. Some new features of the groundwater-lake system in the BJD were found (Wang et al., 2014; Zhang et al., 2015a, b) through in-situ observations on wells, springs and lakes as well as through the long-term monitoring on groundwater and lake water level at typical lakes. Gong et al. (2014) schematically summarized the role of groundwater in the saline lakes in the BJD. In this paper, we extend the investigation to an integrated analysis on the role of groundwater in lake water-salt balances in the BJD, with up-to-date observation data. The objective of this study is to obtain more robust and quantitative answers against the above three questions as to the effects of groundwater on hydrological and chemical behaviors of the lakes.

\section{Study area and methods}

\subsection{Study area}

As shown in Fig. 1a, the BJD $\left(39^{\circ} 20^{\prime}-41^{\circ} 30^{\prime} \mathrm{N}, 100^{\circ} 01^{\prime}-103^{\circ} 10^{\prime} \mathrm{E}\right)$, partly a Gobi desert, lies in the western Alxa Plateau in Inner Mongolia, China. It covers an area of $4.9 \times 10^{4} \mathrm{~km}^{2}$ and is the second largest desert in China (Wang, 1990). The downstream area of the Heihe River connects with the BJD along the Gurinai Lake area. On the north, east and south sides, the BJD is embraced by mountains that were mainly formed by granite rocks. The highest elevation of the mountains around the BJD is about $1,750 \mathrm{~m}$, whereas the ground surface elevation of the BJD is $950-1,400$ m.

The groundwater-fed lakes are concentrated in the southeast part of the BJD (Fig. 1b), near the Yabrai Mountain. At least 119 lakes could be identified on the 30-m resolution remote sensing images in this area. In general, a lake approximately exhibits a circle shape in plan. The characteristics of the three largest lakes are listed in Table 1. Nuoertu Lake is the largest one with 
an area of $1.65 \mathrm{~km}^{2}$. Most of the lakes are smaller than $0.2 \mathrm{~km}^{2}$ and shallower than $2 \mathrm{~m}$. More than $65 \%$ of the lakes are saline lakes (TDS $>35 \mathrm{~g} / \mathrm{L}$ ) and the salinities of some lakes are as high as TDS $>300 \mathrm{~g} / \mathrm{L}$. There are a few subsaline lakes with TDS $<3 \mathrm{~g} / \mathrm{L}$. It is interesting to notice that in some places a subsaline lake may be very close to a hypersaline lake. For example, near the south edge of the lake-group area, the East Badain Lake has a low salinity of less than $2 \mathrm{~g} / \mathrm{L}$, whereas the salinity of the West Badain Lake (about $200 \mathrm{~m}$ away from the East Badain Lake) is higher than $50 \mathrm{~g} / \mathrm{L}$.

The high salinity feature of the lakes is corresponding to the extremely dry climate in the BJD. In general, precipitation only occurs in summer (from June to August) with a mean annual precipitation less than $100 \mathrm{~mm}$. The amount of precipitation decreases from the south to the north and the mean annual precipitation is less than $50 \mathrm{~mm}$ along the north boundary of the desert. The meteorological data from the national meteorological station in the capital town of Alxa Right Banner represents the conditions at the south-edge of the BJD. The mean annual precipitation at the site is $116 \mathrm{~mm}$, which is tiny in comparison with the mean annual pan evaporation of 3,452 $\mathrm{mm}$ observed with a standard 20 -cm-diameter pan. Such a high potential evaporation seems not to be caused by a high air temperature because the mean air temperature in summer is not higher than $24^{\circ} \mathrm{C}$; but may link with the high wind speed, which is $4.4 \mathrm{~m} / \mathrm{s}$ on average and could be higher than $20 \mathrm{~m} / \mathrm{s}$ when storms strike. The strong wind plays an important role in occurrence of the mega-dunes in the BJD. Many sand dunes are $300 \mathrm{~m}$ tall or more (Wang, 1990). It was generally believed that the dunes existed for at least 100,000 years, i.e. they were formed before the Late Pleistocene (Wang, 1990; Dong et al., 2013). However, the dune shapes were continuously altered by winds since the formation of the desert.

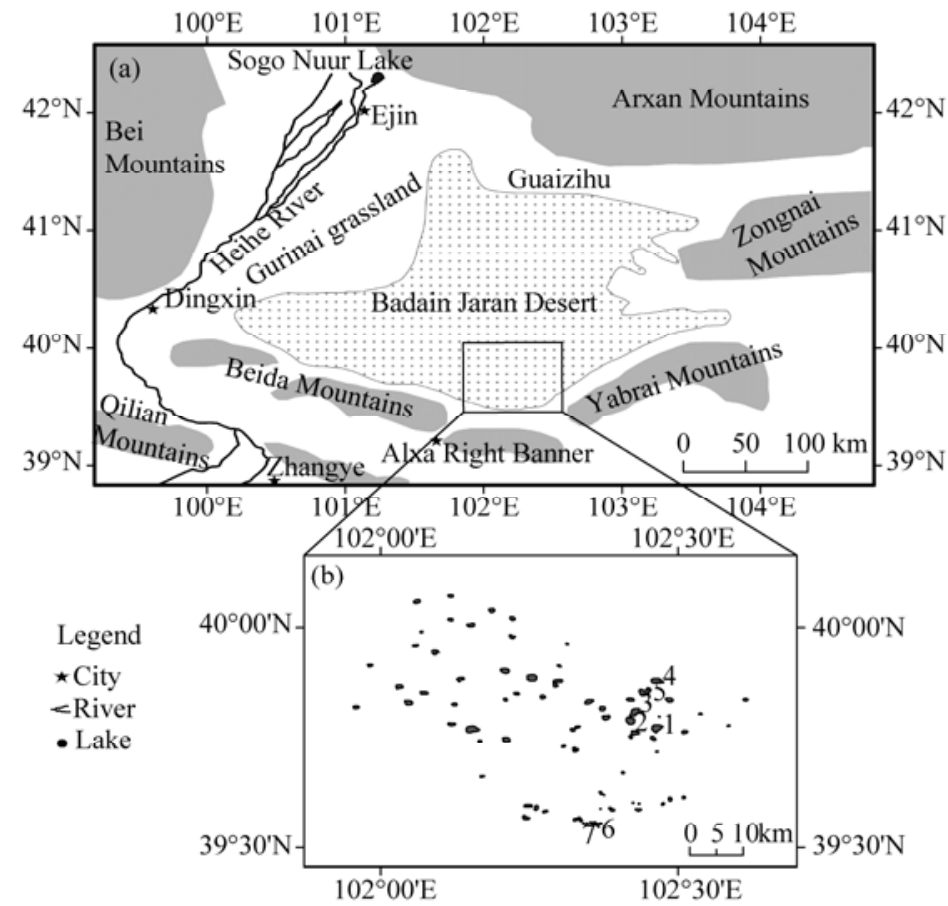

Fig. 1 Schematic map of the Badain Jaran Desert (a) and the lakes (b). The lakes numbered in (b) are: 1, Nuoertu; 2, SumuBarunJaran; 3, SumuJaran; 4, KuheJaran; 5, Yinderrtu; 6, East Badain; 7, West Badain.

Table 1 Characteristis of the largest three lakes in the Badain Jaran Desert

\begin{tabular}{lccccc}
\hline \multirow{2}{*}{ Lakes } & $\begin{array}{c}\text { Area } \\
\left(\mathrm{km}^{2}\right)\end{array}$ & $\begin{array}{c}\text { Water level } \\
(\mathrm{m} \text { asl })\end{array}$ & $\begin{array}{c}\text { Maximum observed } \\
\text { depth }(\mathrm{m})\end{array}$ & \multicolumn{2}{c}{ Total dissolved solids $(\mathrm{g} / \mathrm{L})$} \\
\cline { 5 - 6 } Nuoertu & 1.65 & 1,185 & 15.9 & Lake water & Nearby groundwater \\
SumuBarunJaran & 1.25 & 1,179 & 9.5 & $127.8^{\dagger}$ & $0.5^{\dagger}$ \\
KuheJaran & 1.03 & 1,184 & 11.3 & $109.0^{\dagger \dagger}$ & $0.7^{\dagger}$ \\
\hline
\end{tabular}

Note: ${ }^{\dagger}$ according to Ma and Yang (2008); ${ }^{\dagger \dagger}$ according to Shao et al. (2011). 


\subsection{Observation methods}

The interactions between lake water and groundwater in the BJD were investigated during 2012 2014 via different approaches.

First, a field survey on the hydrogeological conditions in the BJD and surrounding regions was carried out. More than 110 field sites were investigated, including 45 wells, 24 lakes, 16 springs and some geological sites. Among the wells, 4 new boreholes with a total length of $245 \mathrm{~m}$ were drilled to reveal the distribution of sediments and groundwater level in the central area of the BJD. These borehole data were combined with the previous hydrogeological data and up-to-date geological survey data as well as the remote sensing data to determine the regional structure of the aquifer system and groundwater flow in the BJD. Some typical results were presented in Wang et al. (2014) and Zhang et al. (2015a, b). It was indicated that the BJD is located in a huge basin with thick aquifers composed of Cretaceous sandstones, Neogene sandy sediments and Quaternary sands. At regional scale, groundwater flow from the east-south to the west-north and the lakes produce a locally low level of water table due to strong evaporation loss (Zhang et al., 2015b). Water samples were collected from the wells, springs and lakes for chemical analysis including isotopes such as ${ }^{2} \mathrm{H},{ }^{3} \mathrm{H}$ and ${ }^{18} \mathrm{O}$. These chemical data and the existing data in the literature were used to study the interactions between lakes and groundwater in the BJD.

Second, the hydraulic and chemical characteristics of the lake-groundwater system were observed in detail across some lakes, for example, in a basin with two lakes where the south lake is named SumuBarunJaran and the north lake is named SumuJaran (Fig. 1b). In September 2013, the depth dependent distributions of temperature and water electric conductivity were measured across the SumuBarunJaran Lake where a sub-lake spring was identified (Chen et al., 2015). Similar measurements were also carried out in the SumuJaran Lake. Piezometers were installed on the banks of the lakes to determine the hydraulic gradient. Measurement on the profiles can figure out the lake shapes and clearly present the relationships between the groundwater and the lakes.

Long-term monitoring was conducted with respect to typical lakes. In 2012, an automatic meteorological station was installed above the water table in the SumuBarunJaran Lake. In particular, an E601-type evaporation pan $(60 \mathrm{~cm}$ in diameter) was fixed in the lake to measure the actual evaporation rate of lake water. Fluctuation of the lake water level was observed with sensors that installed near the bottom of the lake. Change in groundwater level near the lake was measured in a 16-m-depth piezometer. In the East Badan Lake, the fluctuation of the lake water level, temperature and electric conductivity were observed using multiple sensors for two years. These long-term monitoring on lakes and groundwater provided dynamic data for analysis on the interactions between groundwater and lakes.

\section{Results}

\subsection{Groundwater discharge to lakes via springs}

The lakes in the BJD are fed by groundwater through several basic groundwater discharge routes, seepage faces, springs and vertical seepage across the lakebed. The springs are relatively small places where groundwater flows out of the aquifers in a concentrated way. They are essential for researchers to directly observe and measure groundwater discharge.

In the BJD, springs were found near lakes or even within lakes. A spring can be exposed in a pit that not far away from a lake and forms a creek toward the lake. The Bayannur Lake is fed by such a spring as shown in Fig. 2a. Discharge rate of groundwater toward the spring was measured as $95-130 \mathrm{~m}^{3} / \mathrm{d}$ (Gao et al., 1981). Springs also formed just on the back of a seep zone on the bank of a lake or within the seep zone as shown in Fig. 2b. In this situation, groundwater is exposed in several small ponds surrounding with grasses. Sometimes, groundwater can flow upward in a small island that is located almost in the center of a lake. An example of such a spring is shown in Fig. 2c. The outlet of the spring is about $20 \mathrm{~cm}$ higher than the lake level, indicating an artesian condition of groundwater below the lakebed. The island was formed by calciferous sediments that deposited when groundwater (TDS, $0.81 \mathrm{~g} / \mathrm{L}$ ) touched the high salinity (TDS, ca $250 \mathrm{~g} / \mathrm{L}$ ). This 
process is relevant to the ionic strength effect for calcite dissolution in solution mixtures with different levels of salinity (Sanz et al., 2011).
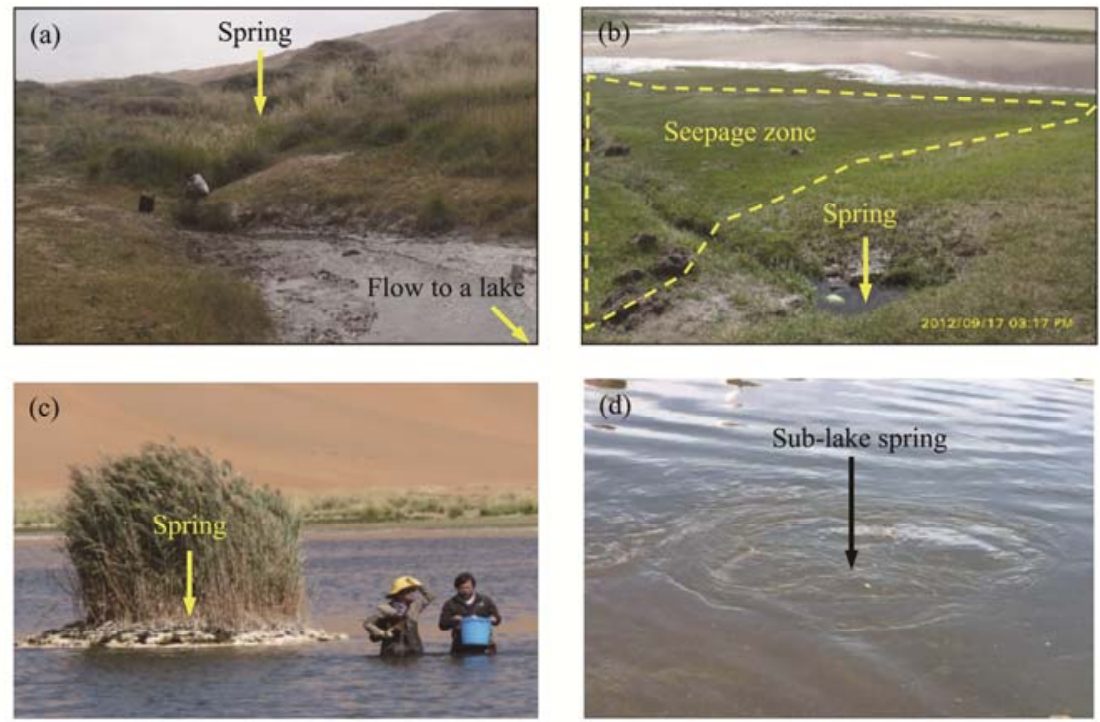

Fig. 2 Typical springs in the Badain Jaran Desert (BJD): near the Bayannur Lake (a); near the Geriletu lake (b); in the Yindeertu Lake (c); in the SumuJaran Lake (d)

Sublacustrine springs belong to a special type of springs that developed on the bottom of lakes (Kresic and Stevanovic, 2010). When the lake water is shallow, a sublacustrine spring can make upwelling flow and create circular waves on the lake surface, through which the spring can be identified. Several sublacustrine springs were found in the SumuJaran Lake as shown in Fig. 2d. A profile investigation was carried out across one of the springs and the results are shown in Fig. 3. The piezometers, L1, L2 and L3, were drilled with a hand-driven auger and were installed using PVC pipes (diameter, $5 \mathrm{~cm}$ ). Soil samples were collected in $20-\mathrm{cm}$ intervals to check the sediment variations with the depth. As revealed, sediments on the site are composed of aeolian sands with a calcareous cementation interbed. In L1, the depth of the calcareous layer is $110 \mathrm{~cm}$ and the thickness of this interbed is about $5 \mathrm{~cm}$. The calcareous cementation might be the sediments deposited on the paleo-lakebed in the history of the SumuJaran Lake. Similar calcareous sediments were also found on the slope of sand dunes as an evidence of that higher lake level existed thousands years ago (Yang et al., 2010). In the area of L1, L2 and L3, the calcareous layers incline to the lake and seem extend into the lake area but were broken at the location of the sublacustrine springs. Due to significantly low permeability, the calcareous cementation functions as a confining unit and creates a weak artesian condition of groundwater in the underlying sands. As a result, groundwater can discharge from a broken area and the water pressure is a little bit higher than the weight of the lake water, producing a circulation flow in the cone-shaped space over the spring. The piezometer L3 was penetrated 1-m-depth into the lakebed. It showed a relatively steady groundwater level, which is $11 \mathrm{~cm}$ above the lake level.

Sublacustrine springs can also develop in the deep area of the lakes but it is difficult to find them. However, the significant salinity differences between groundwater and lake water is an advantage for identifying the deep sublacustrine springs. In September 2012, a measurement on the depth dependent temperature and salinity on a profile across the SumuBarunJaran Lake was undertaken (Fig. 4). On the bank of the lake, as shown in Fig. 4b, a 16-m-depth borehole was installed as the observation well for long-term groundwater monitoring. The TDS of groundwater in W7 is less than $1 \mathrm{~g} / \mathrm{L}$ whereas the TDS of the lake water is $60-160 \mathrm{~g} / \mathrm{L}$. It was found that abnormal low TDS zones exist near the lake bottom as shown in Fig. 4b. This abnormal low TDS zones could be interpreted by the mixing of sublacustrine springs (Chen et al., 2015). Thus, an 
upward groundwater flow exists under the bed of the SumuBarunJaran Lake. The distribution of temperature in the thermocline obeyed the normal heat conduction driven by seasonal variations of the air temperature (Chen et al., 2015), but was almost not influenced by the springs because the difference of temperature between groundwater and the lake water is not significant at the bottom of the lake.

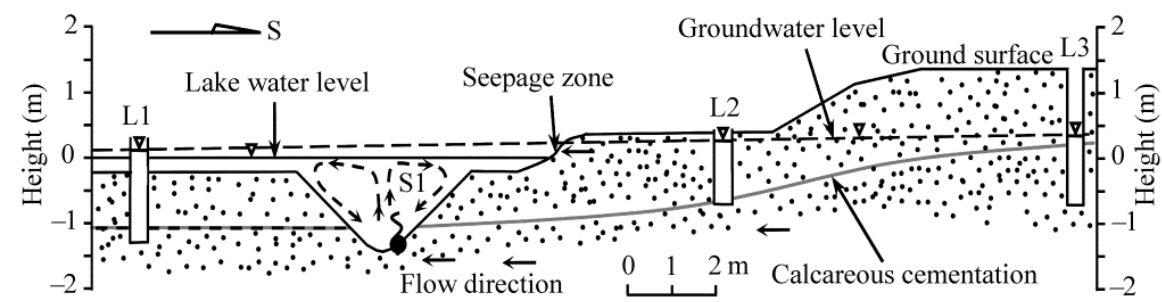

Fig. 3 Hydraulic profile of a sublacustrine spring in the SumuJaran Lake. L1 and L2 are piezometers with a 20 -cm-length screen on the bottom. L3 is a piezometer with only opened bottom.

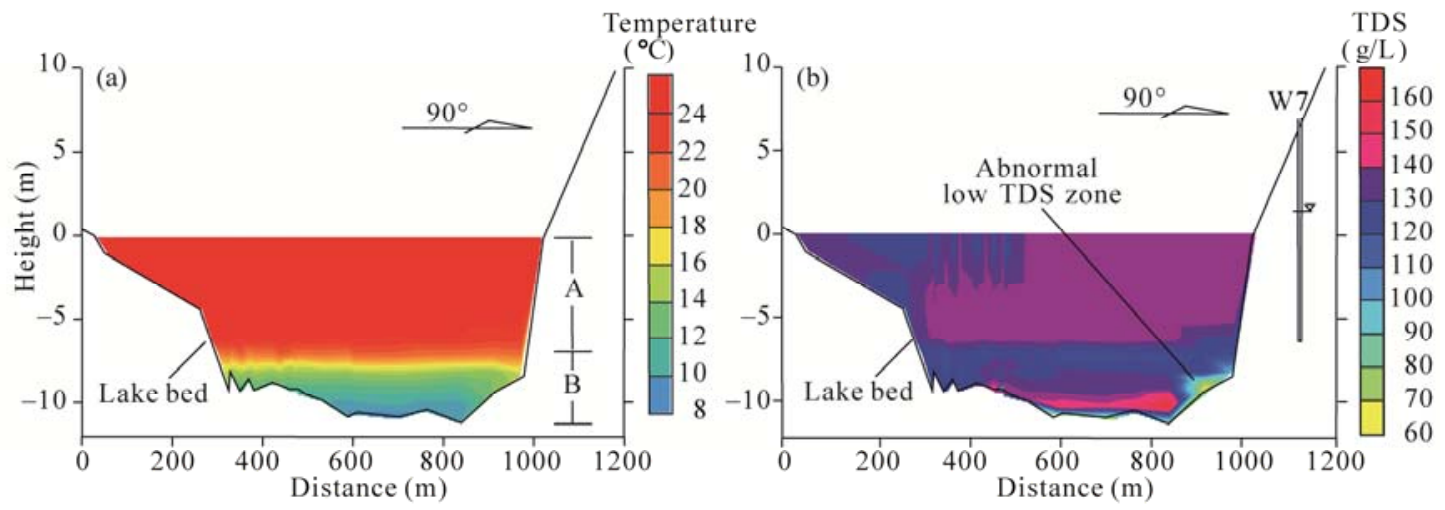

Fig. 4 Temperature (a) and salinity (b; TDS, total dissolved solids) profiles measured in September 2012 in the SumuBarunJaran lake (Chen et al., 2015). Zones A and B in the lake are the mixing layer and thermocline, respectively. W7 is an observation well.

\subsection{Role of groundwater in lake water balances}

\subsubsection{General water balance model for the groundwater-fed lakes}

For an individual groundwater-fed lake in the BJD, the change in total lake water storage is controlled by water inflow and outflow. The inflow includes precipitation and groundwater discharge. The outflow includes evaporation loss and possible surface and/or subsurface runoff if the water level in a lake is higher than that in neighboring lakes. Therefore, the water balance of a lake can be described as Eq. 1,

$$
M_{w}=\rho_{l} A h=M_{w 0}+\left[\rho_{g} q_{g}+\rho_{f} A(P-E)-\rho_{l} q_{s}\right] \Delta t .
$$

Where $M_{w 0}$ and $M_{w}$ are the water masses ( $\mathrm{kg}$ ) of the lake at the beginning and the end for a study period of $\Delta t(\mathrm{~d}) ; A$ is the area of the lake $\left(\mathrm{m}^{2}\right) ; h$ is the average depth of the lake $(\mathrm{m})$ at the end of the period; $\rho_{l}, \rho_{g}$ and $\rho_{f}$ are the densities $\left(\mathrm{kg} / \mathrm{m}^{3}\right)$ of lake water, groundwater and fresh water, respectively; $q_{g}$ is the groundwater discharge rate $\left(\mathrm{m}^{3} / \mathrm{d}\right) ; q_{s}$ is the surface/subsurface runoff rate $\left(\mathrm{m}^{3} / \mathrm{d}\right) ; P$ and $E$ are the precipitation and evaporation rates $(\mathrm{m} / \mathrm{d})$ on lake surface. Since the densities of both lake water and groundwater are not uniformly distributed, $\rho_{l}$ and $\rho_{g}$ represent the average values.

Equation 1 is a general water balance model for an individual groundwater-fed lake in the BJD with varying water volume. When the mean annual water balance behavior under a long-term steady climate is concerned, the change in the lake water storage could be neglected. Then, $M_{w}=M_{w 0}$ can be accepted for the mean annual water balance of a lake. Since the salinity of 
groundwater is generally less than $1 \mathrm{~g} / \mathrm{L}, \rho_{g}$ can be approximated by $\rho_{f}$. Applying the assumptions in Eq. 1, we have

$$
Q_{g}=A\left(E_{a}-P_{a}\right)+\left(\rho_{l} / \rho_{f}\right) Q_{s} .
$$

Where $Q_{g}$ and $Q_{s}$ are the mean annual groundwater discharge $\left(\mathrm{m}^{3} / \mathrm{a}\right)$ and surface/subsurface runoff $\left(\mathrm{m}^{3} / \mathrm{a}\right)$, estimated by $q_{g} \cdot \Delta t$ and $q_{s} \cdot \Delta t$, respectively, where $\Delta t$ is the 1 -year-length time step; $E_{a}$ is the mean annual evaporation loss of lake water $(\mathrm{m} / \mathrm{a}) ; P_{a}$ is the mean annual precipitation $(\mathrm{m} / \mathrm{a})$. The unit of the annual evaporation and precipitation is meters rather than milimeters when Eq. 2 is applied.

When the surface/subsurface runoff can be neglected $\left(Q_{s}=0\right)$ for a closed lake, the mean annual groundwater discharge is simply proportional to the area of the lake for a given value of $\left(E_{a}-P_{a}\right)$. In the lake-group area (Fig. 1b) in the BJD, the mean annual precipitation $\left(P_{a}\right)$ is around $100 \mathrm{~mm}$ whereas the mean annual evaporation $\left(E_{a}\right)$ on the lake water surface is 1,200-1,550 mm (Wang et al., 2014). Accordingly, for a $1-\mathrm{km}^{2}$ lake, the mean annual groundwater discharge would be $1.10 \times 10^{6}-1.45 \times 10^{6} \mathrm{~m}^{3} / \mathrm{a}$. The total area of the lakes in the BJD is about $20 \mathrm{~km}^{2}$, which means that the total groundwater discharge to the lakes could be at least $22.0 \times 10^{6} \mathrm{~m}^{3} / \mathrm{a}$. The contribution of direct precipitation would be about $2.0 \times 10^{6} \mathrm{~m}^{3} / \mathrm{a}$. Thus, groundwater discharge contributes more than $90 \%$ of water inflow in the lakes in the BJD.

\subsubsection{Water balance of the SumuBarunJaran Lake}

The SumuBarunJaran Lake is a closed saline lake which has been particularly observed in recent years. An automatic weather station was installed on a platform in the lake since 2012 where the precipitation is monitored by a self-recording pluviometer. An E601-type evaporation pan was installed in the lake (the rim of the pan is about $30 \mathrm{~cm}$ higher than the maximum lake level) near the weather station, which approximately measured the lake water evaporation The monthly pan-evaporation data of 2012-2013 have been used by Wang et al. (2014) for analyzing the annual water balance of the lakes in the BJD. The changes in the lake level was also measured by a CTD-Diver, a pressure sensor, that was installed near the bottom of the lake at the edge of the weather station. A 16-m depth piezometer, W7 (Fig. 4) was installed on the bank of the lake (Wang et al., 2014; Chen et al., 2015) with a Mini-Diver, another type of pressure sensor, to measure the changes in the groundwater level. CTD-Diver and Mini-Diver are similar sensors (Waterloo Hydrogeologic Inc., Canada) for monitoring water temperature $\left( \pm 0.1^{\circ} \mathrm{C}\right)$ and pressure $( \pm 0.5 \mathrm{~cm}$ $\mathrm{H}_{2} \mathrm{O}$ ) whereas CDT-Diver can also record the electric conductivity of water ( $\pm 1 \%$ of reading). The up-to-date observation data are shown in Fig. 5.

No surface water flow was found in the SumuBarunJaran Lake. We assumed that $q_{s}=0$ for this lake. To simulate the monthly variations of the lake water level, Eq. 1 is rewritten as a different form versus time as Eq. 3,

$$
h_{m}=h_{m 0}+\frac{\rho_{f}}{A \rho_{l}}\left[q_{g, m} \Delta t+A\left(P_{m}-E_{m}\right)\right] .
$$

Where $m$ is the index of month, $\Delta t$ is the number of days in a month, $h_{m}$ is the lake level (m) at the end of the month, $h_{m 0}$ is the initial value of the lake level for this month (equal to the result of the $m-1$ month), $q_{\mathrm{g}, m}$ is the average discharge rate $\left(\mathrm{m}^{3} / \mathrm{d}\right)$ of groundwater during the month, $P_{m}$ and $E_{m}$ are the monthly precipitation (m) and evaporation (m). It is assumed in Eq. 3 that the lake area, $A$, and the average density of the lake water, $\rho_{l}$, are constant. According to the water salinity of the SumuBarunJaran Lake, the approximate value of $\rho_{l} / \rho_{f}$ is 1.13. In this study, the relationship between the groundwater discharge flux, $q_{\mathrm{g}} / A$, and the groundwater level is assumed as,

$$
\frac{q_{g, m}}{A}=\lambda_{g}\left(H_{m}-h_{m}\right) \text {. }
$$

Where $H_{m}$ is the groundwater level (m) observed at the end of the month by the piezometer (W7); $\lambda_{g}$ is a constant coefficient (/d). Substituting Eq. 4 into Eq. 3, we have 


$$
h_{m}=\frac{\rho_{l} h_{m 0}+\rho_{f}\left[\lambda_{g} H_{m} \Delta t+\left(P_{m}-E_{m}\right)\right]}{\rho_{l}+\lambda_{g} \rho_{f} \Delta t} .
$$

Equation 5 can be applied to simulate the monthly changes of lake levels for a known initial level using observed $P, E$ and $H$.
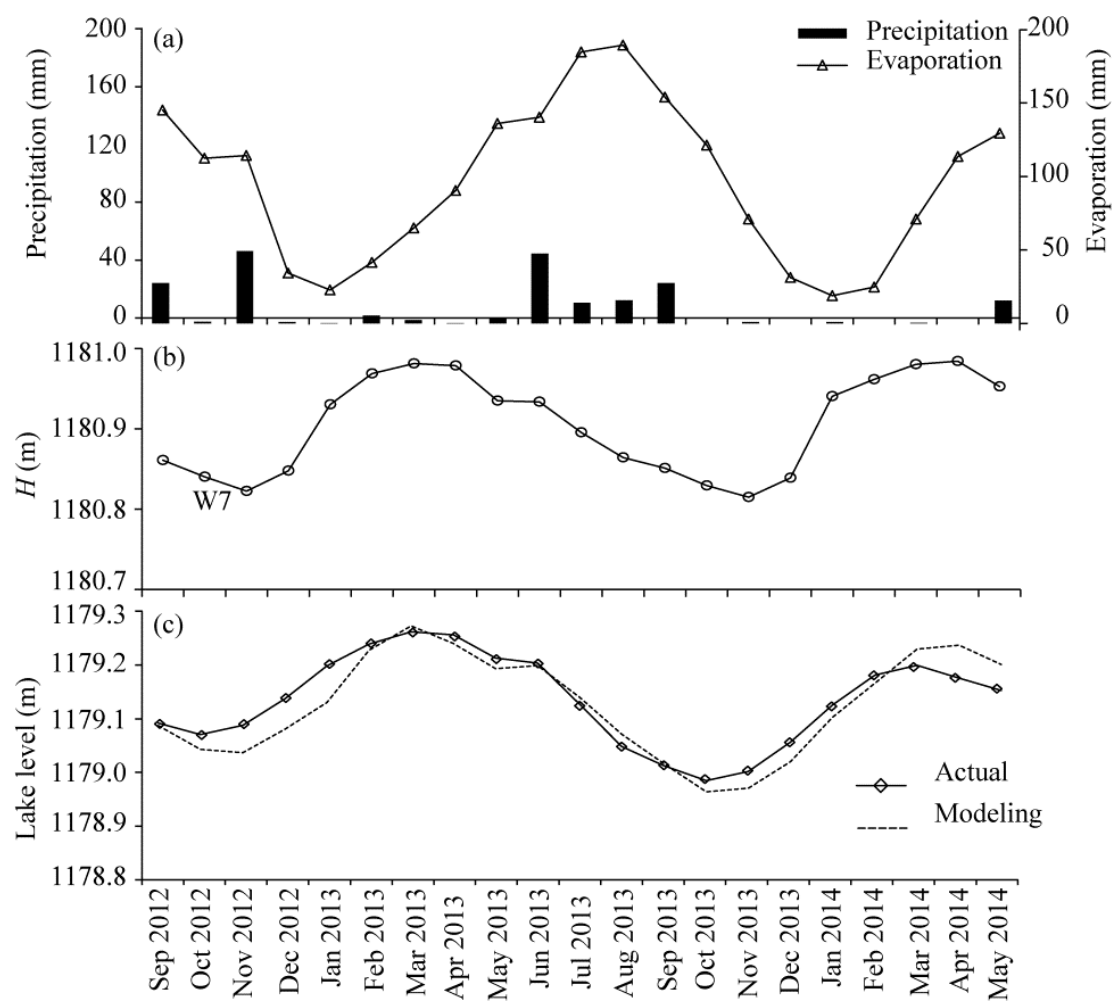

Fig. 5 The variations of precipitation and evaporation in the SumuBarun Lake (a), the near-lake groundwater level $(H)$ in W7 (b), and the lake level (c) during 2012-2014. The modeling lake level in (c) was based on the water balance model.

The monthly water balance model of the SumuBarunJaran Lake was calibrated with the observed data of the lake level during 2012-2014. It can be seen in Fig. 5 that both the groundwater and lake levels decreased in summer due to heavy evaporation and increased in winter, with a small fluctuation amplitude $(<0.3 \mathrm{~m})$. The mean difference between $H$ and $h$ during 2013 is $1.78 \mathrm{~m}$. As shown in Fig. 5c, the modeling results are consistent with the observed variations of the lake levels in general. The average absolute error is $2.6 \mathrm{~cm}$, less than $10 \%$ of the fluctuation amplitude. It demonstrates that Eq. 5 is an applicable approximation in representing the dynamic behavior of the groundwater-lake system. The coefficient, $\lambda_{g}$ (Eq. 4) was estimated as $0.001577 / \mathrm{d}$ or $0.58 / \mathrm{a}$. The groundwater discharge rate can be estimated by Eq. 4 as $1.27 \times 10^{6} \mathrm{~m}^{3} / \mathrm{a}$ in average using the known parameter value $A=1.24 \mathrm{~km}^{2}$ and the mean $H-h=1.78 \mathrm{~m}$. The predicted flux of groundwater discharge, $q_{g} / A=1,024.6 \mathrm{~mm}$, is close to the actual annual evaporation $(1,222.3 \mathrm{~mm})$ minus the actual annual precipitation $(115.0 \mathrm{~mm})$ in 2013 . Variations in groundwater discharge can be estimated as $3,480.8 \pm 138.3 \mathrm{~m}^{3} / \mathrm{d}$ according to the observed groundwater and lake levels during 2012-2014. The standard deviation of $q_{g}$ is less than 5\% of the mean value, which indicates an approximately steady sate of groundwater discharge.

\subsection{The role of groundwater in salt balance of the lakes}

2.3.1 The salts in the groundwater and the lakes

The chemical characteristics of the lakes and groundwater in the BJD have been well analyzed in the literature based on large number of samples (Wang, 1990; Yang et al., 2003; Gates et al., 2008; 
Ma and Yang, 2008; Lu et al., 2010; Shao et al., 2011). During 2012-2014, further samples were collected for analysis on the major ion/anion chemistry. The 67 lake-water samples and 45 groundwater samples were collected for analyzing the characteristics of salts in the groundwater-lake system in the BJD. Part of the samples was collected from the same lakes but at different times during 1999-2014. The ranges of major ion/anion contents in the samples of the hypersaline lakes, the subsaline to mesosline lakes and groundwater were summarized in Table 2 and Fig. 6. Classification of the saline lakes refers to Hammer (1986). It can be seen that groundwater is rich in $\mathrm{Na}^{+}+\mathrm{K}^{+}$and $\mathrm{HCO}_{3}{ }^{-}+\mathrm{CO}_{3}{ }^{2-}$ but no dominant anion type. In the groundwater, the $\mathrm{Cl}^{-}$concentration is generally less than $500 \mathrm{mg} / \mathrm{L}$ whereas the $\mathrm{HCO}_{3}^{-}+\mathrm{CO}_{3}{ }^{2-}$ concentration could be greater than $600 \mathrm{mg} / \mathrm{L}$. It indicates that groundwater is sufficiently opening to the atmosphere in the recharge processes. In the hypersaline lakes, the $\mathrm{HCO}_{3}{ }^{-}+\mathrm{CO}_{3}{ }^{2-}$ concentration is generally less than the $\mathrm{Cl}^{-}$concentration but could be larger than the $\mathrm{SO}_{4}{ }^{2-}$ concentration and the ions are significantly dominant by $\mathrm{Na}^{+}$. Therefore, the hypersaline lakes fall in the chemical category of $\mathrm{Na}^{+}-\mathrm{Cl}^{-}$, which implies the impact of strong evaporation in a closed landscape. In comparison with groundwater and the hypersaline lakes, the subsaline to mesosaline lakes show more complex characteristics in chemistry. As shown in Fig. 6, the maximum $\mathrm{SO}_{4}{ }^{2-}$ concentration approximately shows a linear correlation with the minimum $\mathrm{Cl}^{-}$concentration, indicating that the $\mathrm{SO}_{4}{ }^{2-}$ variability is also significantly controlled by evaporation.

Table 2 Summary of salts in the lakes and groundwater in the BJD

\begin{tabular}{lccc}
\hline \multirow{2}{*}{ Components } & \multicolumn{2}{c}{ Lakes } & \multirow{2}{*}{ Groundwater } \\
\cline { 2 - 3 } $\mathrm{nH}$ & Hypersaline lakes & Subsaline to mesosaline lakes & \\
$\mathrm{nyD}(\mathrm{g} / \mathrm{L})$ & $9.5-11.0$ & $7.2-11.0$ & $7.7-8.4$ \\
$\mathrm{Na}(\mathrm{g} / \mathrm{L})$ & $66.0-483.0$ & $1.5-28.0$ & $<1.3$ \\
$\mathrm{Ca}+\mathrm{Mg}(\mathrm{g} / \mathrm{L})$ & $37.0-220.0$ & $<10.0$ & $<0.4$ \\
$\mathrm{~K}(\mathrm{~g} / \mathrm{L})$ & $<4.0$ & $<0.9$ & $<0.2$ \\
$\mathrm{Cl}(\mathrm{g} / \mathrm{L})$ & $<19.2$ & $<0.6$ & $<0.1$ \\
$\mathrm{CO}_{3}(\mathrm{~g} / \mathrm{L})$ & $10.0-247.0$ & $<51.0$ & $<0.5$ \\
$\mathrm{HCO}_{3}(\mathrm{~g} / \mathrm{L})$ & $0.5-102.2$ & $<32.8$ & $<0.1$ \\
$\mathrm{SO}_{4}(\mathrm{~g} / \mathrm{L})$ & $0.4-29.8$ & $<33.4$ & $<0.5$ \\
\hline
\end{tabular}

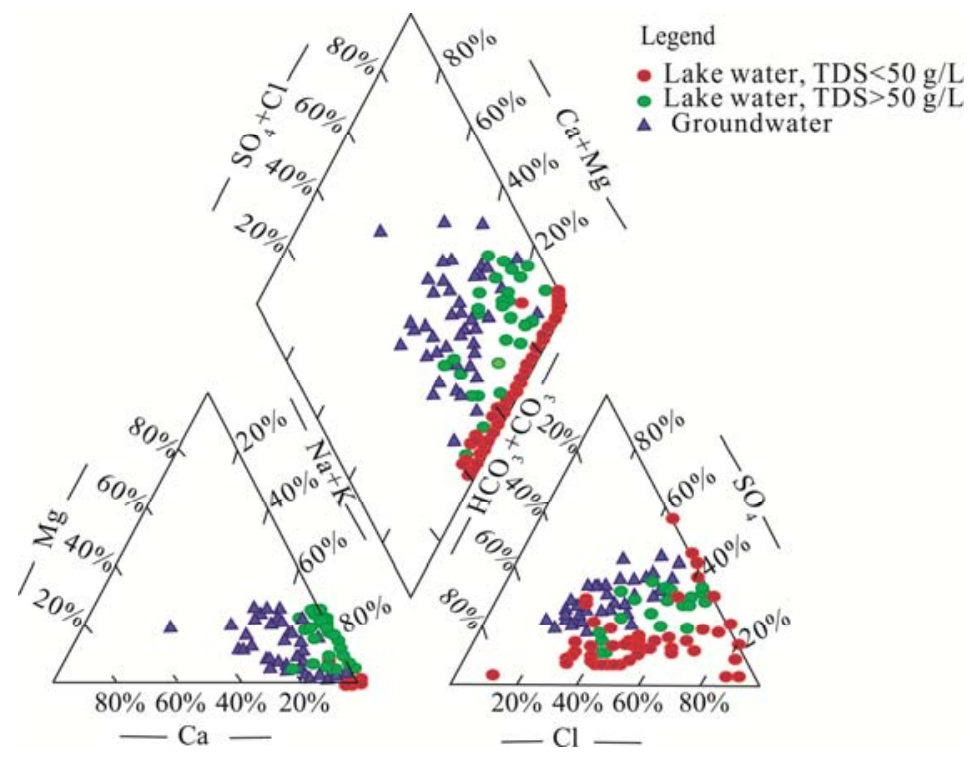

Fig. 6 Piper chart comparing groundwater and lake water samples in the BJD

2.3.2 General salt balance model for groundwater-fed lakes

It is well known that the high salinity of a saline lake is generally caused by accumulation of salts 
over a long-term evaporation process in a relatively closed environment. For an individual groundwater-fed lake, salts were mainly brought by groundwater discharge whereas a little of them originated from dry/wet deposition. During the evaporation, the lake losses pure water but the salts are accumulated so that the salinity increases. Some of the ions/anions, e.g. $\left(\mathrm{Ca}^{2+}+\mathrm{Mg}^{2+}\right)-\mathrm{CO}_{3}{ }^{2-}$, would deposited when the salinity is high enough. With development of the salinization, $\mathrm{Na}^{+}-\mathrm{Cl}^{-}$will finally become the dominant components because of their high solubility.

According to the gain-loss of salts, the salt-mass changes of a lake for a selected component can be described as,

$$
M_{s}=C_{l} A h=M_{s 0}+\left[C_{g} q_{g}+C_{r} A P-C_{l} q_{s}+A\left(n_{p}-n_{d}\right)\right] \Delta t .
$$

Where $M_{s}$ is the total salt-mass $(\mathrm{kg})$ of the component in the lake at the end of the study period; $M_{s 0}$ is the initial total mass $(\mathrm{kg})$ in the lake for the period; $\mathrm{C}_{l}, C_{g}$ and $C_{r}$ are the concentrations $\left(\mathrm{kg} / \mathrm{m}^{3}\right)$ of the salts in the lake water, groundwater and precipitation, respectively; the $C_{r} A P$ term denotes the wet deposition of the component; $n_{p}$ and $n_{d}$ are the intensity $\left(\mathrm{kg} /\left(\mathrm{m}^{2} \cdot \mathrm{d}\right)\right)$ of the dry deposition from the atmosphere to the lake and the intensity $\left(\mathrm{kg} /\left(\mathrm{m}^{2} \cdot \mathrm{d}\right)\right)$ of salt deposition from the lake water to the lakebed for the studied components. The TDS in rain samples in the Alxa area was detected as $40-80 \mathrm{mg} / \mathrm{L}$, with $18-30 \mathrm{mg} / \mathrm{L} \mathrm{HCO}_{3}{ }^{2-}, 4-22 \mathrm{mg} / \mathrm{L} \mathrm{Cl}^{-}, 3-17 \mathrm{mg} / \mathrm{L} \mathrm{SO}_{4}{ }^{2-}, 7-18$ $\mathrm{mg} / \mathrm{L} \mathrm{Ca}^{2+}+\mathrm{Mg}^{2+}$ and 5-20 mg/L Na ${ }^{+}+\mathrm{K}^{+}$(Gates et al., 2008). Dry deposition of the salts occurs when the dune sand deposition is accompanied by the deposition of wind-eroded salty dust that partly originated from playas in the BJD (Yang et al., 2010). Deposition of sediments in the lakes, forming calcareous layers or crystal salt layers on the lakebeds, removes salts from the lake water. In particular, the deposition may be controlled by biological processes because a halophilism species (Artemiasalina) lives in the saline lakes. However, it is difficult to give a quantitative analysis on the values of $n_{p}$ and $n_{d}$ before more complicated investigations. As estimated in Section 2.2.1, total groundwater discharge to the lakes in the BJD is at least $22.0 \times 10^{6} \mathrm{~m}^{3} / \mathrm{a}$, whereas the contribution of direct precipitation is only about $2.0 \times 10^{6} \mathrm{~m}^{3} / \mathrm{a}$. According to these inflow data and the TDS values of groundwater and rains, the contributions of salts from groundwater and precipitation into the lakes would be higher than $11.0 \times 10^{6} \mathrm{~kg} / \mathrm{a}$ and less than $0.2 \times 10^{6} \mathrm{~kg} / \mathrm{a}$, respectively. Thus, more than $98 \%$ of the salts in the lakes were brought by groundwater in the BJD.

\subsubsection{Relative salt accumulation time of the lakes}

Equation 6 reveals that the salt accumulation in a lake is dominated by the continuous input of salts from groundwater discharge and other sources. Since most of the lakes in the BJD are saline lakes, the time-scale of the salt accumulation in the lakes is an interesting question. It involves the complex history of the landscape and lakes in the desert. However, it is plausible to assess the salt accumulation process of a lake from the fresh to the saline status using the salt input rate at present for an investigated lake (Langbein, 1961; Yechieli and Wood, 2002). In this study, we defined a relative accumulation time, $\Delta t_{R}$, of the salts in a lake by rewriting Eq. 6 as the follow,

$$
\Delta t_{R}=\frac{M_{s}-M_{s 0}}{C_{g} q_{g}+C_{r} A P-C_{l} q_{s}+A\left(n_{p}-n_{d}\right)} .
$$

Where $M_{s}$ and $M_{s 0}$ are the total amount of salt-mass in the lake at present $\left(=C_{l} A h\right)$ and at the beginning with only fresh groundwater. For a closed lake, it is assumed that $q_{s}=0$. However, in general, the effect of $n_{p}-n_{d}$ is not significant in comparison with the contribution of groundwater and surface water inflow for closed lakes (Langbein, 1961; Wood and Sanford, 1990; Yechieli and Wood, 2002) so that it is neglected in this study. Under a stable climate condition, groundwater discharge would be balanced by evaporation minus precipitation, i.e. $q_{g} / A=E-P$. According to these simplifications, Eq. 7 can be replaced by

$$
\Delta t_{R} \approx \frac{\left(C_{l}-C_{g}\right) h}{C_{g}(E-P)+C_{r} P} .
$$


The mean annual water balance of a lake is incorporated into Eq. 8, which reveals that the relative accumulation time mainly depends on the average depth of lake water, the concentrations of the selected components from different water sources and the precipitation-evaporation fluxes.

The conservative anion $\mathrm{Cl}^{-}$was selected to calculate the relative accumulation time to minimize the errors in the estimation. The mean annual precipitation and evaporation of the lake water were assumed as $100 \mathrm{~mm}$ and 1,200-1,550 mm, respectively. The value of $\mathrm{C}_{\mathrm{r}}$ was specified as $10 \mathrm{mg} / \mathrm{L}$ in average for the rain water samples. Concentrations of $\mathrm{Cl}^{-}$in the lakes and groundwater were given according to the data of the detected samples. In this study, we analyzed the water samples from 5 lakes using this proposed method (Table 3 ). The relative accumulation time $\left(\Delta t_{R}\right)$ of the lakes are generally longer than 1,000 years, indicating that the salinization processes of the lakes continued for a long time. The maximum relative accumulation time is close to 7,000 years. The large varying range of the $\Delta t_{R}$ may also imply that the lakes were formed at different times, for example, the Nuoertu Lake may be significantly older than the SumuJaran Lake.

Table 3 The relative accumulation time estimated for typical saline lakes

\begin{tabular}{lccccc}
\hline Lakes & $\begin{array}{c}\text { Area } \\
\left(\mathrm{km}^{2}\right)\end{array}$ & $\begin{array}{c}\text { Average lake } \\
\text { depth }(\mathrm{m})\end{array}$ & $\begin{array}{c}\mathrm{Cl}^{-} \text {in lake water } \\
(\mathrm{g} / \mathrm{L})\end{array}$ & $\begin{array}{c}\mathrm{Cl}^{-} \text {in groundwater } \\
(\mathrm{g} / \mathrm{L})\end{array}$ & $\begin{array}{c}\Delta t_{R} \\
(\mathrm{a})\end{array}$ \\
\hline SumuBarunJaran & 1.3 & $8 \pm 2$ & 39.5 & 0.119 & $1,366-2,995$ \\
SumuJaran & 0.6 & $5 \pm 1$ & 40.5 & 0.119 & $933-1,842$ \\
KuheJaran & 1.0 & $7 \pm 2$ & 29.4 & 0.126 & $800-1,895$ \\
Yindeertu & 0.9 & $6 \pm 2$ & 81.4 & 0.087 & $2,561-6,734$ \\
Nuoertu & 1.7 & $14 \pm 1$ & 33.6 & 0.094 & $3,181-4,828$ \\
\hline
\end{tabular}

Note: $\Delta t_{R}$, relative accumulation time.

\section{Discussion}

There are two sources of uncertainties should be highlighted in estimating groundwater discharge from the water balance model in this study.

The first uncertainty was that the lake water evaporation loss has not been exactly estimated or measured. There were different reported data in the literature for the lake surface evaporation in the BJD. Chen et al. (2006) presumed that the potential evaporation on land surface was higher than $3,500 \mathrm{~mm} / \mathrm{a}$ and took the $60 \%$ of that as the rate of lake water evaporation $(2,100 \mathrm{~mm} / \mathrm{a})$. It was a very rough assessment because the mechanism of the actual evaporation processes was not considered. Yang et al. (2010) estimated the lake surface evaporation using Penman equation and obtained the estimated annual evaporation $\left(E_{a}\right)$, which was $840-1,260 \mathrm{~mm}$ with $1,040 \mathrm{~mm}$ in average. This result was less than half of that applied by Chen et al. (2006). The new estimated annual evaporation $\left(E_{a}, 1,375 \mathrm{~mm}\right.$ in average) presented by Wang et al. (2014) was obtained through an E601-type pan installed in one of the lakes. It was much closer to the average $E_{a}$ value estimated by Yang et al. (2010) rather than that presumed by Chen et al. (2006). On land surface, the E601-pan evaporation overestimates the evaporation on open water bodies under the same meteorological conditions and the pan coefficient was recommended to be 0.83 in the Inner Mongolia and Xinjiang areas (Shi et al., 1986). If this pan coefficient is applied for the pan used in the SumuBarunJaran Lake, the $E_{a}$ value would be $1,141 \mathrm{~mm}$. The main reason for the overestimation of the pan evaporation is the higher thermal-energy gain in the pan than in the natural surface water body. However, the E601-pan applied by Wang et al. (2014) was installed in the lake rather than on the land surface, leading to similar thermodynamic and aerodynamic conditions between the pan and the lake. Thus, the normal pan effect could be significantly reduced. This E601-pan evaporation was the most realistic result at present because it was observed mostly near the natural circumstances of the lakes. In the previous analysis, we assumed that the pan coefficient of the E601-pan in the SumuBarunJaran Lake is 1.0. While a smaller pan coefficient is applied, the estimated groundwater discharge will decrease. If the pan coefficient is 0.9 , we can obtain the best fitting $\lambda_{g}$ value is $0.001405 / \mathrm{d}$ or $0.51 / \mathrm{a}$. The estimated groundwater discharge then will decrease to $1.12 \times 10^{6} \mathrm{~m}^{3} / \mathrm{a}$ in average. Therefore, the range of $1.1 \times 10^{6}-1.3 \times 10^{6}$ 
$\mathrm{m}^{3} / \mathrm{a}$ is more realistic for groundwater discharge in the SumuBarunJaran Lake.

The second uncertainty is the simplification on the lake-groundwater interactions in the water balance model. The assumption of $q_{s}=0$ would be false for some specific lakes with obvious outflow or inflow from surface water. In addition, $\rho_{l}$ should not be regarded as a constant if the average salinity of a lake exhibits significant seasonal variations. This would occur for lakes with shallow water table or with surface water flow. Equation 4 yields a simple way to calculate groundwater discharge from the observed groundwater level near a lake. It would be reasonable for groundwater discharge along the lake margin whereas would be too simple for groundwater discharge through sublacustrine springs because the mechanism is not very clear and the observations of deep groundwater were not available. The model could be improved when more synthetic investigations on the interactions between the lakes and groundwater in the BJD are carried out in further studies.

For the saline lakes in the BJD, the relative accumulation time shown in Table 3 is far from the real time of the salinization history, due to the simplifications in Eq. 8. However, the preliminary results show the evolution process of saline lakes (Yechieli and Wood, 2002). Further investigations are required to provide more realistic estimation of the salt accumulation history for the lakes in the BJD.

\section{Conclusions}

In the BJD, groundwater contributes more than $90 \%$ of water and most of the salts in the lakes. Groundwater discharge is not in a uniform way but generally concentrated into springs, including sublacustrine springs that exist even 10-m-depth below the lake water surface. As indicated by the simplified water balance model in this study, the groundwater discharge rate in a closed lake is almost steady so that the seasonal change in the lake water level is not significant even the annual evaporation of lake water can be higher than $1,000 \mathrm{~mm}$. The salinity of groundwater is low, but the import of salts from this continuous groundwater discharge leads to a long-term increasing trend of the lake water salinity. Using a simple model for the salt accumulations in the lakes, the relative accumulation time was estimated as 800-7,000 years for typical saline lakes. It indicates a long history of the salt accumulation process from the beginning moment when the lakes were fresh and closed.

Further investigations are required to reveal the more complicated interaction behaviors between lakes and groundwater. The preliminarily estimated salt accumulation time, represented by the $\mathrm{Cl}^{-}$accumulation, is only an approximation. It could be improved by using synthetic evolution information of the groundwater-lake system in the BJD.

\section{Acknowledgments}

This study was supported by the China Foundation for the Author of National Excellent Doctoral Dissertation (201457) and the National Natural Science Foundation of China (91125024). The authors are grateful to the two anonymous reviewers for their constructive comments on improving the presentation.

\section{References}

Chen J S, Li L, Wang J Y, et al. 2004. Water resources: Groundwater maintains dune landscape. Nature, 432(7016): 459-460.

Chen J S, Zhao X, Sheng X F, et al. 2006. Formation mechanisms of megadunes and lakes in the Badain Jaran Desert, Inner Mongolia. Chinese Science Bulletin, 51(24): 3026-3034.

Chen T F, Wang X S, Hu X N, et al. 2015. Clines in salt lakes in the Badain Jaran Desert and their significances in indicating fresh groundwater discharge. Journal of Lake Science, 27(1): 183-189. (in Chinese)

Dong Z B, Qian G Q, Lv P, et al. 2013. Investigation of the sand sea with the tallest dunes on Earth: China's Badain Jaran Sand Sea. Earth-Science Reviews, 120: 20-39.

Gao Z, Xie R, Shang X, et al. 1981. Regional hydrogeological survey on the Nuergai Area. In: China Geological Survey Report $\mathrm{J}-47-[6]$. Beijing, China. (in Chinese)

Gates J B, Edmunds W M, Daling W G, et al. 2008. Conceptual model of recharge to southeastern Badain Jaran Desert 
groundwater and lakes from environmental tracers. Applied Geochemistry, 23(12): 3519-3534.

Geyh M A, Gu W Z, Liu Y, et al. 1998. Isotopically anomalous groundwater of Alxa Plateau, Inner Mongolia. Advances in Water Science, 9(4): 333-337. (in Chinese)

Gong Y P, Wang X S, Chen T F, et al. 2014. The role of groundwater in the salt lakes in the Badain Jaran Desert, China. Acta Geologica Sinica, 88(S1): 70.

Hammer U T. 1986. Saline Lake Ecosystems of the World. New York: Springer, 15.

Jiao J J, Zhang X T, Wang X S. 2015. Satellite-based estimates of groundwater depletion in the Badain Jaran Desert, China. Scientific Reports, 5: 8960.

Jin X M, Gao M M, Ke K, et al. 2014. Extraction of remote sensing information of lakes in Badan Jaran Desert and trend of their dynamic changes. Science \& Technology Review, 32(8): 15-21. (in Chinese)

Kresic N, Stevanovic Z. 2009. Groundwater Hydrology of Springs: Engineering, Theory, Management, and Sustainability. Oxford, UK: Elsevier Inc., 459-461.

Langbein W B. 1961. Salinity and hydrology of closed lakes. Geological Survey Professional Paper 412, 1-19.

Lu Y, Wang N A, Li G P, et al. 2010. Spatial distribution of lakes hydro-chemical types in Badain Jaran Desert. Journal of Lake Science, 22(5): 774-782. (in Chinese)

Ma J Z, Edmunds W M. 2006. Groundwater and lake evolution in the Badain Jaran Desert ecosystem, Inner Mongolia. Hydrogeology Journal, 14(7): 1231-1243.

Ma N N, Yang X P. 2008. Environmental isotopes and water chemistry in the Badain Jaran Desert and in its southeastern adjacent areas, Inner Mongolia and their hydrological implications. Quaternary Sciences, 28(4): 702-711. (in Chinese)

Mischke S, Demske D, Wünnemann B, et al. 2005. Groundwater discharge to a Gobi desert lake during Mid and Late Holocene dry periods. Palaeogeography, Palaeoclimatology, Palaeoecology, 225(1-4): 157-172.

Rosen M R. 1994. The importance of groundwater in playas: A review of playa classifications and the sedimentology and hydrology of playas. Geological Society of America Special Publication, 289: 1-18.

Sanz E, Ayora C, Carrera J. 2011. Calcite dissolution by mixing waters: geochemical modeling and flow-through experiments. Geologica Acta, 9(1): 67-77.

Shao T J, Zhao J B, Dong Z B. 2011. Water chemistry of the lakes and groundwater in the Badain Jaran Desert. Acta Geographica Sinica, 66(5): 662-672. (in Chinese)

Shi C X, Niu K Y, Chen T Z, et al. 1986. The study of pan coefficients of evaporation pans of water. Scientia Geographica Sinica, 6(4): 305-313. (in Chinese)

Sun D, Tian R, Li Z, et al. 1961. Regional geological and hydrogeological survey in the West Inner Mongolia Plateau. In: China Geological Survey No. 1243. Beijing, China. (in Chinese)

Wang T. 1990. Formation and evolution of Badain Jaran Sandy Desert, China. Journal of Desert Research, 10(1): 29-40. (in Chinese)

Wang X S, Hu B X, Jin X M, et al. 2014. Interactions between groundwater and lakes in Badain Jaran Desert. Earth Science Frontiers, 21(4): 91-99. (in Chinese)

Wood W W, Sanford W W. 1990. Ground-water control of evaporite deposition. Economic Geology, 85(6): 1226-1235.

Yang X P. 2002. Water chemistry of the lakes in the Badain Jaran Desert and their Holocene evolutions. Quaternary Sciences, 22(2): 97-104. (in Chinese)

Yang X P, Ma N N, Dong J F, et al. 2010. Recharge to the inter-dune lakes and Holocene climatic changes in the Badain Jaran Desert, western China. Quaternary Research, 73(1): 10-19.

Yang X P, Williams M A J. 2003. The ion chemistry of lakes and late Holocene desiccation in the Badain Jaran Desert, Inner Mongolia, China. Catena, 51(1): 45-60.

Yechieli Y, Wood W W. 2002. Hydrogeologic processes in saline systems: playas, sabkhas, and saline lakes. Earth-Science Reviews, 58(3-4): 343-365.

Zhang Z, Dong Z B, Yan C Z, et al. 2015. Change of lake area in the southeastern part of China's Badain Jaran Sand Sea and its implications for recharge sources. Journal of Arid Land, 7(1): 1-9.

Zhang J, Wang X S, Jia F C, et al. 2015a. New insights into the flow directions of groundwater in Western Alxa, Inner Mongolia. Geoscience, 29(1): 213-219. (in Chinese)

Zhang J, Wang X S, Hu X N, et al. 2015b. The macro-characteristics of groundwater flow in the Badain Jaran Desert. Journal of Desert Research, 35(3): 774-782. (in Chinese)

Zhu J F, Wang N A, Li Z L, et al. 2011. RS-based monitoring seasonal changes of lake in Badain Jaran Desert. Journal of Lake Sciences, 23(4): 657-664. (in Chinese) 